Bangladesh J. Bot. 50(3): 865-872, 2021 (September) SpecialＤOI: https://doi.org/10.3329/bjb.v50i5.56438

\title{
TEMPORAL AND SPATIAL VARIATION CHARACTERISTICS OF SOIL MECHANICAL COMPOSITION AFTER AEOLIAN SOIL IMPROVEMENT BY SOFT ROCK IN MU US SANDY LAND
}

\author{
Haiou Zhang ${ }^{1,2,3^{*}}$, Tingting CaO ${ }^{1,2,3}$, XiaOmei Sun $^{2,3}$ and Yan XU $\mathrm{X}^{1,2,3}$ \\ Institute of Land Engineering and Technology, Shaanxi Provincial Land Engineering \\ Construction Group Co. Ltd., Xi'an 710021, Shaanxi Province, China
}

Keywords: Sand, Soft rock, Reconstructed soil, Mechanical composition, Development trend

\begin{abstract}
Based on the field experiment of compound soil with volume mixing ratio of soft rock and sand of $1: 1$, $1: 2,1: 5$ from 2010 to 2018 , the spatio-temporal characteristics and development trend of the mechanical composition of the compound soil with different proportions were studied. The driving factors of the good development of potato growth-compound soil mechanical composition were also explored. Results showed that there was a significant positive correlation between silt-clay mass fraction and cultivation years, the annual variation rates of silt-clay mass fraction were 3.02, 3.90 and $4.11 \%$ in $1: 1,1: 2$, and $1: 5$ of compound soil. At the initial stage of mixing, clay and silt contents of the compound soil in different proportions were $1: 1>1: 2>1: 5$, and 9 years after planting, clay and silt contents were $1: 5>1: 2>1: 1$, potato growth promoted the development of $1: 5$ compound soil mechanical composition more significantly. The downward migration of silt and clay content in the $0-30 \mathrm{~cm}$ surface soil made a relatively dense argic horizon in the $30-40 \mathrm{~cm}$ soil layer, which effectively prevented water and fertilizer downward movement and the migration of fine particles in the surface soil. After years of planting, the thickness of the sandy land plow layer has increased to $45 \mathrm{~cm}$, and the three-proportion compound soil mechanical composition developed to a good condition suitable for crop growth, and did not need to be compounded again after many years.
\end{abstract}

\section{Introduction}

The area of China's deserts and sandy land is about $7.33 \times 10^{7}$ ha, accounting for $7.7 \%$ of the country's land area, among which the Mu Us Desert, one of the four sandy lands, covers about $4.22 \times 10^{6}$ ha. For a long time, preventing land desertification, alleviating environmental pressure, increasing the area of arable land, and implementing comprehensive sand management has always been a focus of social concern and a problem that needs to be solved. Han et al. $(2012,2015)$ found that there were a large number of alternating distribution of soft rock and sand, and the two characteristics are complementary in the Mu Us sandy land, and the soft rock is mixed with the aeolian sandy soil in a certain proportion to construct soil environmental conditions such as suitable water, fertilizer, air and heat for the normal growth of plants, the scientific goal of "promoting sand to form soil" has been realized. Li et al. (2017) found that under the guidance of sand fixation, the optimal compounding proportion of soft rock to aeolian sandy soil is $1: 1$ to 1 : 5 , which has the strongest water-retaining and water-holding functions.

The composition of soil mechanism has a decisive influence on the production and development of soil, and it is an extremely important soil internal properties, its particle size composition and content are important factors for soil physical and chemical properties, which affect soil moisture, air, heat movement, and nutrient transformation, and also affects the type of

\footnotetext{
*Author for correspondence: <academic_our@163.com>, <244254409@qq.com>. ${ }^{1}$ Shaanxi Provincial Land Engineering Construction Group Co. Ltd., Xi'an 710075, China. ${ }^{2}$ Key Laboratory of Degraded and Unused Land Consolidation Engineering, the Ministry of Natural and Resources of China, Shaanxi, Xi'an 710021, China. ${ }^{3}$ Shaanxi Provincial Land Consolidation Engineering Technology Research Center, Shaanxi, Xi' an 710075, China.
} 
soil structure (Xu et al. 2013, Meysam et al. 2019). Su et al. (2018) pointed out that soil mechanical composition is an important indicator to measure soil development, especially the formation and change of clay is the development process of soil, the richer the clay, the more stable the development of soil structure. Deng et al. (2014) found that soil physical, chemical and other properties are also different due to different mechanical composition of soil. The compound soil of soft rock and sand is a sort of new artificial soil, and the primary thing is to optimize the particle composition of aeolian sand soil. Moreover, the development trend of the compound soil mechanical composition in the long-term utilization process needs to be studied emphatically. Existing studies have mainly focused on the nutrient characteristics of compound soil with soft rock and sand (Wang et al. 2017, Sun and Han 2018, Guo et al. 2019), but there are only few studies on its structural development and stability. Thus the present study was undertaken on the field location experiment of $1: 1,1: 2,1: 5$ compound soil under the potato planting model from 2010 to 2018. The temporal and spatial change characteristics and development trend of the mechanical composition of compound soil in different proportions were studied and also the key driving factors for the good development of compound soil-vegetation system were explored. This study would provide a scientific basis for sustainable utilization of the compound soil and the management of the desertified land in China.

\section{Materials and Methods}

The Mu Us Sand Area is mainly located in the depression of the lacustrine alluvial plain between the Ordos Plateau and the Loess Plateau, with an altitude of 1100-1300 meters. The annual precipitation shows a significant difference. The autumn (especially August) precipitation is almost 60 to $75 \%$ of the annual precipitation. Droughts and floods often occur, and there are more droughts than floods. In addition, combined with the characteristics of sufficient light conditions and shallow groundwater in this area, it can meet the conditions for high production and growth of crops. The study area is dominated by aeolian sandy soil, with serious water and fertilizer leakage and large evapotranspiration, resulting in frequent soil drought. The soft rock alternately distributed with aeolian sand soil has low structural strength, poor water permeability, soft and easy to be weathered, but it has good water-holding capacity. The core of the compound soil of soft rock and sand lies in the increase of the content of secondary clay minerals, especially montmorillonite, which is composed of water-bearing aluminosilicate layered minerals. Han et al. (2012) studied the soft rock in the Mu Us sandy land and found that the secondary clay minerals in soft rock are as high as $16.8-46.4 \%$ and the content of clay is as high as $10.3-30.3 \%$. However, more than $95 \%$ of the sand belong to primary minerals with particle size of $0.05 \sim 1 \mathrm{~mm}$ and clay content as low as $0.8 \%$. The soft rock and sand soil were mixed in a certain proportion to form the compound soil for this experiment.

In 2010, a long-term location test plot of compound soil was established, with an area of $12 \mathrm{~m}$ length $\times 5 \mathrm{~m}$ width. According to the experimental requirements, only the $0-30 \mathrm{~cm}$ soil layer of the original sandy land was compounded according to the volume ratio of soft rock to sand at $1: 1$, $1: 2$ and $1: 5$, the soil was fully mixed by mechanical rake. Three repeated test plots were set up in each proportion, and a total of 9 test plots were planted with potato, the main local agricultural crop. Planting can be carried out when the surface soil temperature of $5-10 \mathrm{~cm}$ is $10 \sim 12^{\circ} \mathrm{C}$, and the suitable time for local planting is late April, and the seedlings can be planted with precision amount by artificial ditching. For all plots the same irrigation and fertilization treatments were used, before planting, ditching and applying basal fertilizer. Urea $300 \mathrm{~kg} / \mathrm{ha}$, diammonium phosphate $375 \mathrm{~kg} / \mathrm{ha}$, and potash fertilizer $180 \mathrm{~kg} / \mathrm{ha}$ were applied. Time and amount of irrigation according to the dry weather and the needs of crop growth were determined. Usually, it is appropriate to maintain 75 to $80 \%$ of the maximum field water holding capacity in the soil layer of 
$60 \mathrm{~cm}$. Potatoes were generally irrigated before sowing, seedling stage, tuber formation stage and starch accumulation stage, respectively.

In the experiment, the "S"-shaped sampling method was used after potato harvest in mid-October every year. The soil samples of 0-60 cm soil layer were collected respectively, with 3 points collected under each treatment, and they were taken back to the laboratory for soil physics and nutrient index determination. The collected soil samples were removed from grass roots and other debris, dried naturally, ground through a $2 \mathrm{~mm}$ sieve. The soil mechanical composition was measured using the Malvern laser particle size analyzer, and the average value was calculated for the data obtained from 3 repetitions.

\section{Results and Discussion}

Soil mechanical composition, as an important indicator of natural soil formation and development, has essential differences between the parent material of soil formation and the later soil development (Meysam et al. 2019). The soft rock and sand compound soil formation technology is to reconstruct the sandy soil structure and mechanical composition of the soil layer in the root zone. In 2010, the clay and silt content of compound soil was: $1: 1>1: 2>1: 5$. With the process of the experiment, the contents of silt and clay in the three proportions of compound soil showed a trend of increasing, while the sand content decreased. This is mainly due to the decomposition of litter in the surface cultivated soil and the application of organic fertilizer during the planting process, which improves the texture and nutrients of the surface soil and increases the stability of the soil structure; Secondly, planting crops on the compound soil can not only effectively prevent the loss of fine particulate matter in the sand, but also promote the deposition of fine particulate matter, thereby increasing fine particulate matter in the sand. In a similar study, Luo et al. (2017) studied the physical properties and growth conditions of the soil at different planting years of Niaowang tea in Karst mountainous areas and found that with the increase of planting seasons for Niaowang tea, the soil generally showed good soil structure. The yield and growth status of Niaowang tea planted for $6-10$ years is the best.

Compared with 2010, after 9 years of planting, the silt content of 1:1 compound soil increased by $134.5 \%$, the clay content increased by $62.7 \%$, and the sand content decreased by $35.1 \%$ (Fig. 1). Over time, the sand content of 1:2 compound soil showed a continuous decreasing trend, the silt content fluctuated slightly among different years, but showed an overall increasing trend, and the clay content showed a continuous increasing trend. Compared with 2010, in 2018, silt content increased by $183.8 \%$, the clay content increased by $116.9 \%$, and the sand content decreased by $40.4 \%$ (Fig. 2). The silt and clay contents of the 1:5 compound soil showed a continuous increasing trend, and reached the maximum value in 2018, compared with 2010, the silt and clay contents increased by 2.27 and 2.30 times, and the sand content decreased by $36.2 \%$ (Fig. 3). In 2018, the clay content was $1: 5>1: 2>1: 1$, and the silt content was $1: 2>1: 1>1: 5$, and there were significant differences among different proportions of compound soil $(\mathrm{p}<0.05)$. The soil mechanical composition developed to a state suitable for crop growth.

Regression analysis was carried out on the sum of silt-clay mass fractions and the planting years in the three proportions of compound soil (Table 1), and the slope of the equation is the annual change rate of silt- clay mass fractions. The results showed that there was a significant positive correlation between the silt-clay mass fractions and planting years, and the annual variation rates of the silt -clay mass fractions in the $1: 1,1: 2$ and $1: 5$ compound soil were 3.02, $3.90,4.11 \%$, respectively. The annual increase rate of $1: 5$ compound soil silt and clay content is greater than $1: 1,1: 2$. The change of compound soil particle composition during crop planting are not only the result of soil structure and quality improvement, but at the same time, this change 
in turn further promotes the virtuous cycle and stability of the soil-vegetation system (Liu et al. 2009, Wang et al. 2014). With the increase in the number of potato planting seasons, the increase rate of silt and clay content compound soil was $1: 5>1: 2>1: 1$. The mixing ratio of soft rock and sand is different, and the compound soil has different characteristics. With the development of the experiment, the soil structure of different texture types develops differently. At the same time, it is also the result of long-term survival adaptation between $1: 5$ compound soil and potato root growth, which has an impact on the development of compound soil and changes the distribution of particles in the soil.

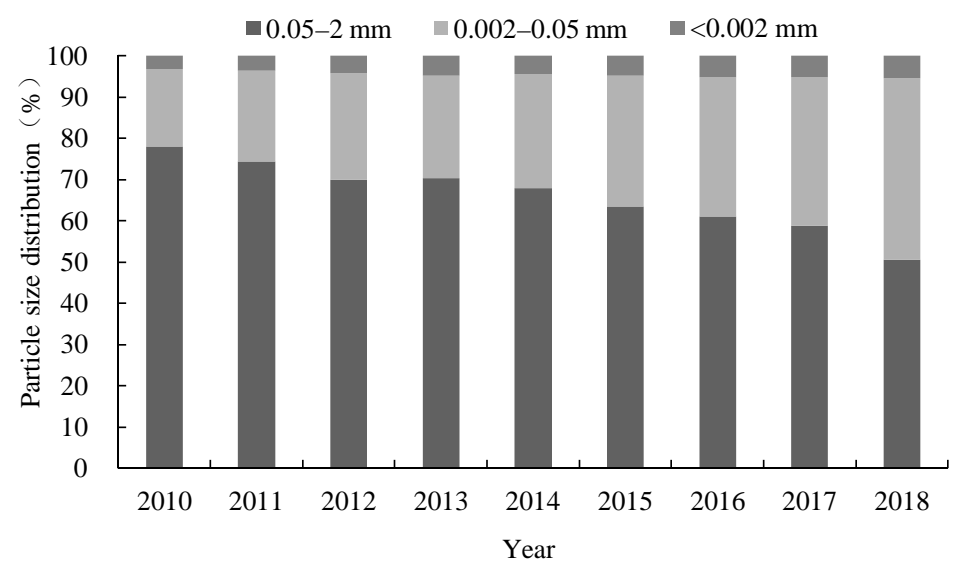

Fig. 1. Particle size composition of 1:1 compound soil under different planting years.

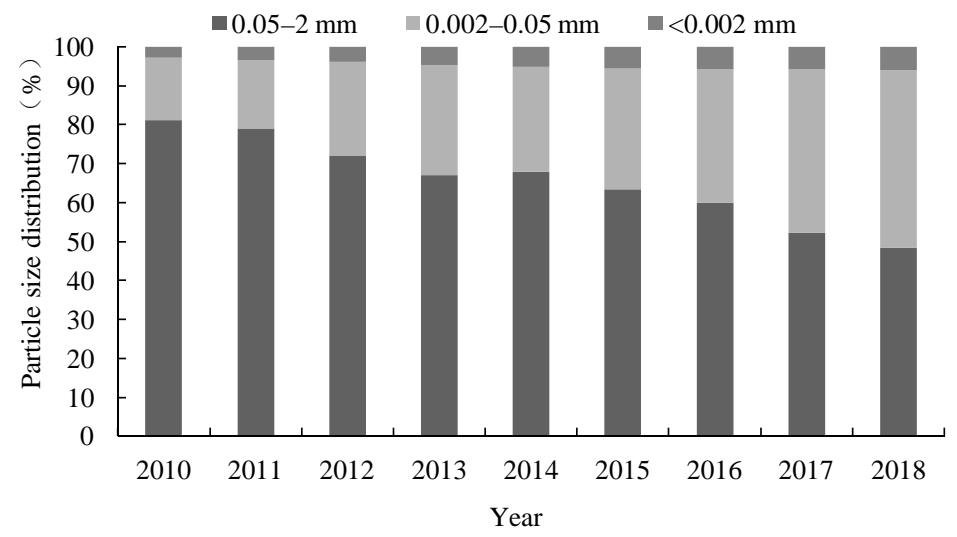

Fig. 2. Particle size composition of 1:2 compound soil under different planting years.

Table 1. Regression analysis of silt-clay mass fractions and the planting years in the three proportions of compound soil.

\begin{tabular}{ccc}
\hline Experimental treatment & Correlation equation & $\mathrm{R} 2$ \\
\hline $1: 1$ & $\mathrm{y}=3.0182 \mathrm{x}+18.873$ & $\mathrm{R} 2=0.9556^{*}$ \\
$1: 2$ & $\mathrm{y}=3.9005 \mathrm{x}+14.423$ & $\mathrm{R} 2=0.9717^{* *}$ \\
$1: 5$ & $\mathrm{y}=4.1088 \mathrm{x}+10.228$ & $\mathrm{R} 2=0.9927^{* *}$ \\
\hline
\end{tabular}




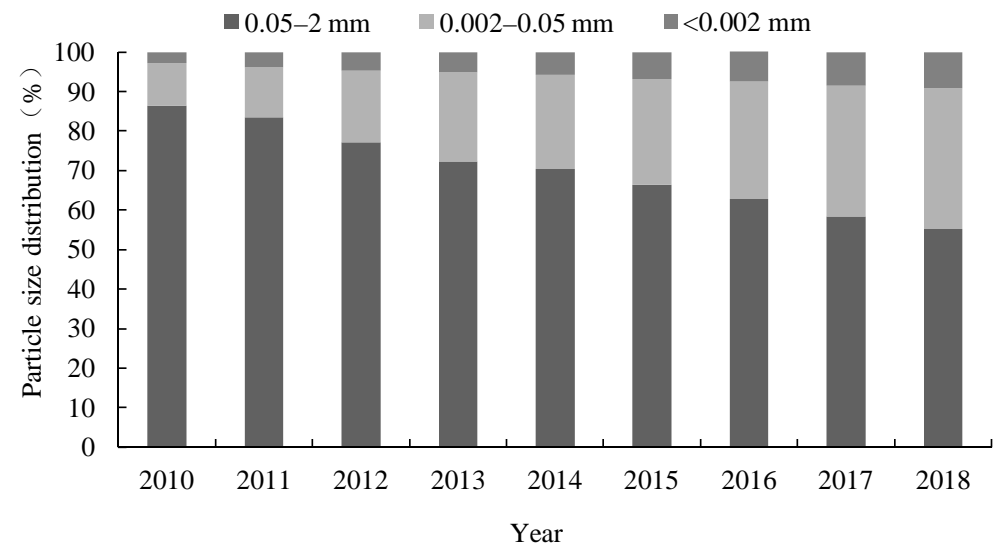

Fig. 3. Particle size composition of 1:5 compound soil under different planting years.

For sandy soil, the formation of the soil has an extremely important relationship with clay and silt content and soil mechanical composition. With the development of the experiment, the silt and clay contents in $0-10 \mathrm{~cm}$ cultivation layer of the three proportions of compound soil fluctuated greatly, and showed a decreasing trend from 2010 to 2013, and then increased slowly after 2014. The silt and clay content in the $10-30 \mathrm{~cm}$ soil layer showed a continuous growth trend, and the increase rate and accumulation amount were higher than other soil layers (Figs 4-6), which was mainly related to the interception effect of potato roots. As the silt and clay content in the surface soil moves downward, the silt and clay content in the $30-40 \mathrm{~cm}$ soil layer increased significantly. From 2016 to 2018, the average silt content of 1:1, 1:2 and 1:5 compound soil in the $30-40 \mathrm{~cm}$ soil layer was $28.43,25.75,19.74 \%$, which were $3.14,3.43$ and 3.65 times of that in 2010 ; the average clay content was $3.69,3.40,4.86 \%$, compared with 2010 and increased by 20.1, 47.6 and $184.2 \%$,

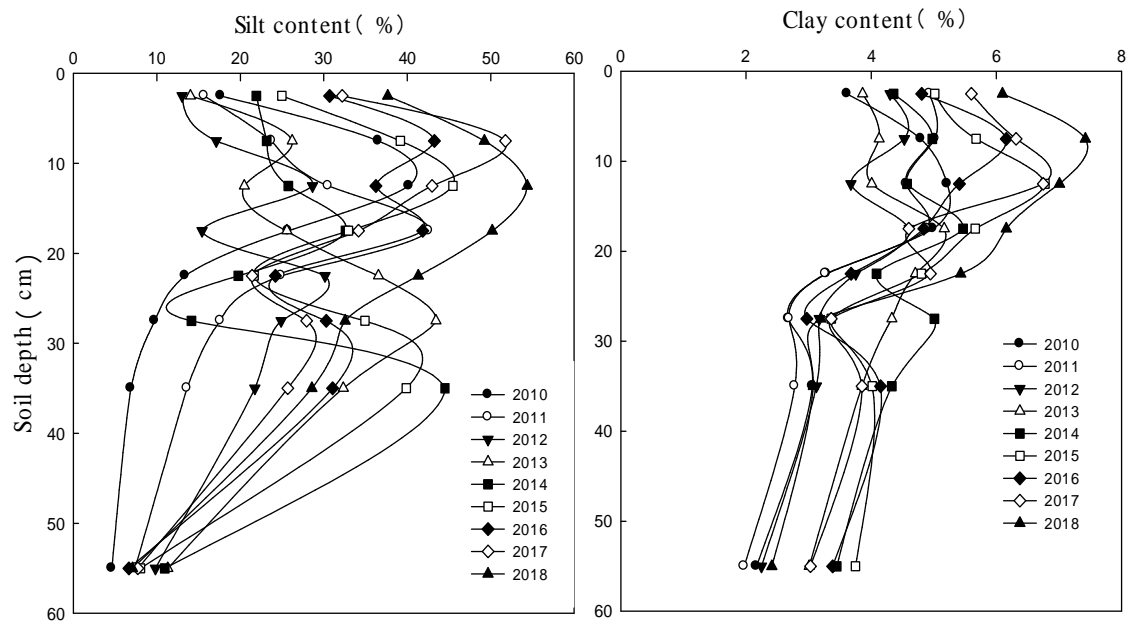

Fig. 4. Migration characteristics of clay and silt in $1: 1$ compound soil. 


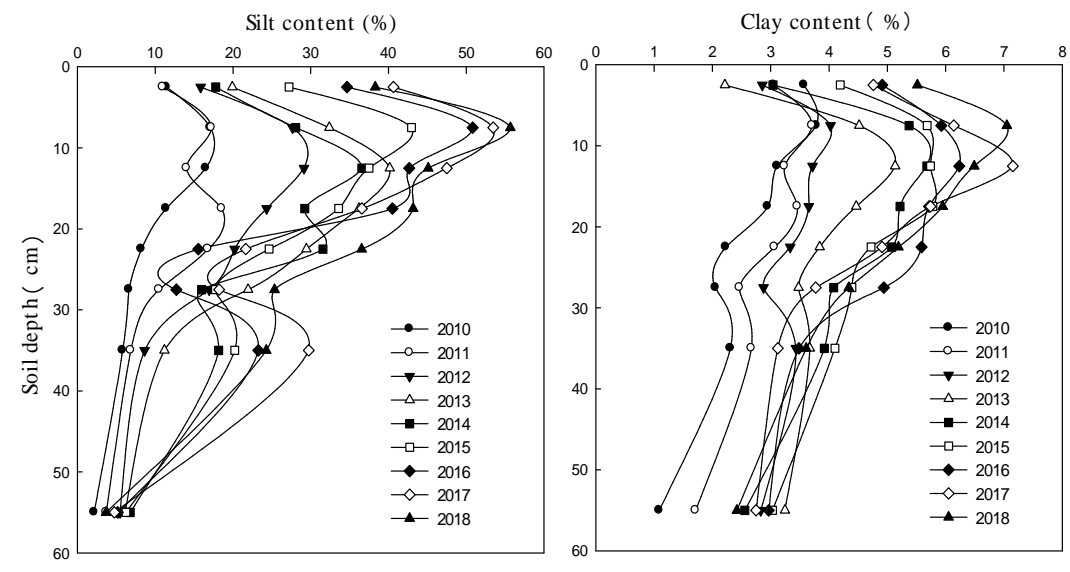

Fig. 5. Migration characteristics of clay and silt in $1: 2$ compound soil.
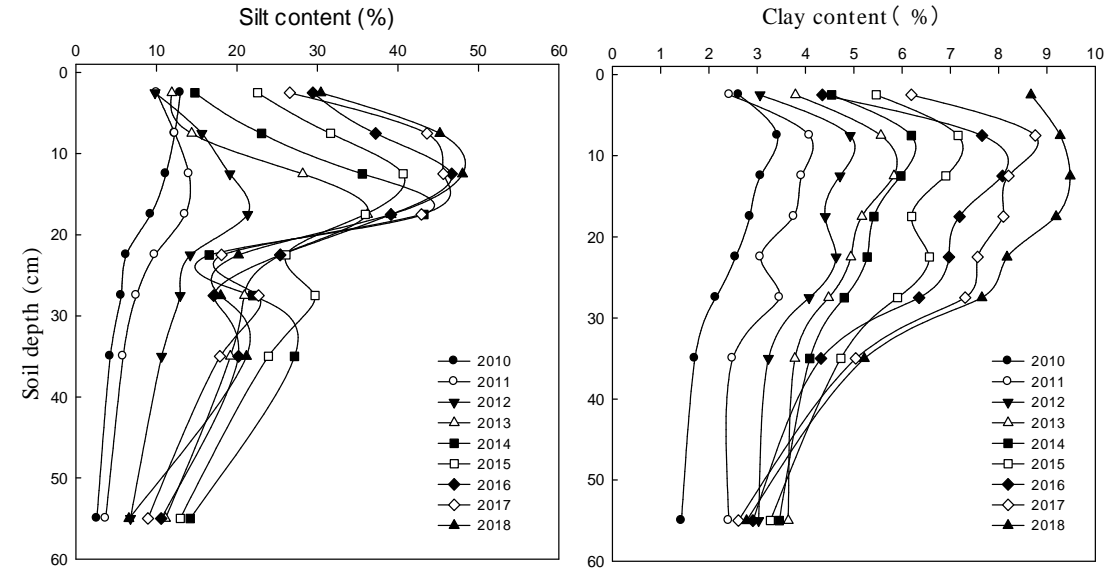

Fig. 6. Migration characteristics of clay and silt in $1: 5$ compound soil.

which meets the demand for crop growth. At the same time, the silt and clay contents in the soil layer below $40 \mathrm{~cm}$ showed a rule of increasing first and then decreasing, but the overall trend was increasing. From 2010 to 2013, the silt and clay content in the soil layer below $40 \mathrm{~cm}$ in the three proportions of compound soil increased significantly, and there was a decreasing trend after 2014. The content of silt and clay in the soil layer below $40 \mathrm{~cm}$ in 2018 were significantly higher than that in 2010, with silt content of $5-7 \%$ and clay content of about $4 \%$, which were still very small and did not meet the demand of crop growth.

The formation of soil is the mixture clay and the change of mechanical composition (Wen et al. 2006, Zhen et al. 2016). The soil layer above $30 \mathrm{~cm}$ is compound soil of soft rock and sand in of the test plot. Due to the addition of soft rock, the content of silt and clay in cultivated layer above $30 \mathrm{~cm}$ was higher than the original sandy land below $30 \mathrm{~cm}$. In the early stage of potato planting, the silt and clay content in the $0-30 \mathrm{~cm}$ soil layer of the three proportions of compound soil migrated faster to the lower soil layer. After 2014, the migration rate of silt and clay particles to the lower soil layer decreased. The main reason is that in the early stage of planting, the newly-created compound soil is in the early stage of development, the soil structure is unstable 
and loose, the soil space is large, with strong sliding properties, so the silt and clay particles are easily washed by rain and migrate to the lower layer. After 2014, the surface soil matrix developed relatively stable, and a relatively dense argic horizon was formed in the $30-40 \mathrm{~cm}$ soil layer. The formation of the argic horizon can effectively prevent the leakage of water and fertilizer and the migration of fine particles in the soil, which is conducive to improving the water and fertilizer conservation of the compound soil.

The combined effect of compound soil cultivation years and potato growth made silt and clay content of the $1: 1,1: 2$ and $1: 5$. Compound soil continues to increase in cultivated layer, and the sand content decreased, especially $1: 5$ compound soil silt and clay content increased at a faster rate. With the development of the experiment, the particle size distribution of compound soil tends to be rationalized, and the soil mechanical composition continued to develop in a good state suitable for crop growth. Silt and clay are the propellants for the healthy cycle and development of the compound soil ecosystem, and the effect of clay is more significant; The downward migration of silt and clay content increased the silt and clay content in the original sandy soil layer below 30 $\mathrm{cm}$, and the thickness of the sandy soil plough horizon increased to $45 \mathrm{~cm}$. The research proved the scientific value and effect of the improvement of sandy soil by soft rock.

\section{Acknowledgements}

This study was financed by Shaanxi Provincial Natural Science Basic Research Program (2021JZ-57), Shaanxi Province Innovative Talents Promotion Plan Young Science and Technology Rising Star Project (2021KJXX-88), Technology Innovation Center for Land Engineering and Human Settlements, Shaanxi Land Engineering Construction Group Co.,Ltd. and Xi'an Jiaotong University (2021WHZ0087), Fund Project of Shaanxi Key Laboratory of Land Consolidation (2019-JC07, 2019-JC08) and Shaanxi Provincial Land Engineering Construction Group internal research project (DJNY2021-25).

\section{References}

Deng TF, Liu Y, Yan QX, He TB and Gao AQ 2014. Mechanical composition and soil nutrient characteristics and their relationships in typical Loniceracinfusa soil of Guizhou. J. Soil Water Conserv. 28(5): 209-214.

Guo Z, Han JC, Li J, Xu Y and Wang XL 2019. Effects of long-term fertilization on soil organic carbon mineralization and microbial community structure. PLoS One 14: e0211163.

Han JC, Liu YS and Zhang Y 2015. Sand stabilization effect of feldspathic sandstone during the fallow period in Mu Us Sandy Land. J. Geogr. Sci. 4: 428-436.

Han JC, Xie JC and Zhang Y 2012. Potential role of feldspathic sandstone as a natural water retaining agent in Mu Us Sandy Land, Northwest China. Chinese Geogr. Sci. 22: 550-555.

Li YR, Fan PC, Cao Z, Chen YF, Liu YS and Wang HY 2017. Sand-fixation effect and micro-mechanism of remixing soil by Pisha Sandstone and sand in the Mu Us Sandy Land, China. J. Desert Res. 37: 421-430.

Luo Q, Zhang ZM, Xiang Z, Zhang JC and He HZ 2017. Soil physical properties of Niaowang Tea growing area with different cultivation years and growth characteristics of Niaowang Tea. Southwest China J. Agr. Sci. 30(12): 2746.

Liu X, Zhang GC and Heathman GC 2009. Fractal features of soil particle-size distribution as affected by plant communities in the forested region of Mountain Yimeng, China. Geoderma 154(1/2): 123-130.

Meysam M, Mahmoud S, Mohammad HM and Nasser D 2019. Characterizing spatial variability of soil textural fractions and fractal parameters derived from particle size distributions. Pedosphere 29: 224-234. 
Sun ZH and Han JC 2018. Effect of soft rock amendment on soil hydraulic parameters and crop performance in Mu Us Sandy Land, China. Field Crops Res. 222: 85-93.

Su ZZ, Liu R, Liang AM, Ma YJ, Wang GL and Gao JL 2018. Study on soil mechanical composition and organic matter of desertification land in Northwest of Shanxi province. Res Soil Water Conserv. 25(6): 61-67.

Wen HY, Fu H and Zhao HL 2006. Fractal features of soil particle size distribution in degraded sandy grassland during reclamation and enclosure. Chinese J. Appl. Ecol. 17(1): 155-59.

Wang HY, Han JC, Tong W, Cheng J and Zhang HO 2017. Analysis of water and nitrogen use efficiency for maize (Zea mays L.) grown on soft rock and sand compound soil. J. Sci. Food Agr. 97(8): 2553-2560.

Wang N, Xie JC, Han JC and Luo LT 2014. A comprehensive framework on land-water resources development in Mu Us Sandy Land. Land Use Policy 40: 69-73.

$\mathrm{Xu}$ GC, Li ZB and Li P 2013. Fractal features of soil particle-size distribution and total soil nitrogen distribution in a typical watershed in the source area of the middle Dan River, China. Catena 101: 17-23.

Zhen Q, Zheng J, He H, Han F and Zhang X 2016. Effects of pisha sandstone content on solute transport in a sandy soil. Chemosphere 144: 2214-2220.

(Manuscript received on 22 June, 2021; revised on 6 October, 2021) 